\title{
Telor Ophthalmic is second quarter's sole IP0
}

Telor

believes that it

can dominate

the market for

elevated-

intraocular-

pressure

therapeutics.
NEW YORK-This year's second quarter saw public financing grind to a halt, with just three companies taking in a paltry $\$ 56.3$ million. Telor Ophthalmic Pharmaceuticals (Woburn, MA) was the quarter's only initial public offering, raising $\$ 23$ million at $\$ 8$ a share. "Our future potential is in the vastly underserved ophthalmic-pharmaceutical market," says Stephen Riggi, Telor's president and chief executive officer. Telor believes that it has a good shot at dominating the market for elevated-intraocularpressure therapeutics, a market that in 1991 amounted to over $\$ 400 \mathrm{mil}$ lion in the U.S. and $\$ 800$ million worldwide. Telor, furthermore, expects that demand for ophthalmic pharmaceuticals will only increase with the aging of developed-nation populations.

The company's strong suit is its exclusive worldwide license for the use of ethancyrnic acid to alleviate elevated intraocular pressure. Ethancyrnic acid was approved 20 years ago by the Food and Drug Administration (FDA, Bethesda, MD) for systemic use as a diuretic for the treatment of hypertension and kidney malfunction. Elevated intraocular pressure is a buildup of fluid in the eye due to blockage of the trabecular meshwork, which normally filters fluid in the aqueous humor as it returns to the bloodstream. Such elevated pressure leads to glaucoma, the leading cause of preventable blindness in the U.S., as well as ocular hypertension, which also often results in glaucoma. Post-cataract-surgery intraocular"spike," moreover, strikes 35-50 percent of cataract-surgery patients.

Telor recently began phase-II clinical trials of Tekron, an ethancyrnicacid-based topical therapeutic for chronic elevated intraocular pressure.Tekron offers a novel approach to reducing intraocular pressure, because unlike conventional therapeutics, which reduce fluid inflow, Tekron is thought to increase fluid outflow, thereby addressing the underlying cause of the condition while treating the symptom. Another advantage of Tekron is that it may be suitable for once-aday administration, as opposed to the multiple daily doses required by most topical glaucoma medications.

Xarano, another Telor therapeutic with the same active ingredient as Tekron, is currently undergoing a 400-patient phase-III trial as a treat- ment for post-cataract-surgery intraocular "spike," a complication for which there is currently noFDAapproved therapy. In a 12-patient phase I/II trial, Xarano-treated patients experienced a peak intraocular pressure increase of less than 10 $\mathrm{mm}$ of mercury a day, on average, while untreated patients showed pressure increases that were two times greater.

Telor has a third product in the clinic, an unnamed compound that may enhance ciliary-muscle contraction and, thus, help focus the lens of the eye. A preclinical feasibility study involving about 25 people is currently underway to assess the compound's ability to treat presbyopia, an age-related impairment of the eye's ability to focus on near objects.

Telor has no collaborations with pharmaceutical firms. Instead, it has collaborative agreements with eight academic and clinical-research institutions, though Riggi declines to name them. Thus far Telor has only lost money, almost $\$ 4$ million last year and over $\$ 7.5$ million since its inception in April 1988. Some analysts see Telor turning its first profit in 1997 . Claire M. Corcoran

\section{Human gene sequencing makes advances}

An alliance is formed to identify useful sequenced genes. And a faster sequencing technique is tested.
FT. COLLINS, Colo.-The drive to commercialize the fruits of the Human Genome Project received good news on two fronts recently. Human Genome Sciences (HGS, Rockville, MD) and SmithKline Beecham (SKB, Philadelphia, PA) formed a strategic alliance that will pump up to $\$ 125$ million of SKB's money into HGS's efforts to identify useful genes sequenced by its parent company, The Institute for Genomic Research (TIGR, Gaithersburg, MD). In return for the cash infusion, SKB will receive an unidentified equity position in HGS and exclusive worldwide rights to therapeutic, vaccine, and diagnostic products and services developed by HGS. HGS, for its part, will receive royalties on sales of future products, will have the option to copromote certain products, and will retain the rights to use genetic data for gene-therapy and antisense applications.

On a second front, researchers at Argonne National Laboratory (Argonne, IL) and the University of Washington (Seattle) announced that they had successfully tested a new DNA sequencing technique, called sequencing by hybridization (SBH), that could identify 100 million base pairs a day when fully implemented. This would represent a 10,000-fold improvement over conventional techniques, 100 times better than researchers had been striving to achieve.

SBH is based on the premise that the human genome, as gigantic as it is, is nevertheless an assembly of overlapping shorter sequences that can be readily identified when hybridized to probes of known composition. Radomir Crkvenjakov, who heads the Argonne effort, and his colleagues use probes containing eight nucleotide bases, known as 8-mers. Though there are 65,635 possible 8-mers of the four nucleotide bases, the Argonne team determined that it is only necessary to use between 100 to 2008 -mers to sequence any given stretch of DNA. In one case, the group sequenced three DNA fragments, each 343 base pairs in length, using only 156 different 8-mer probes. "On average, each base in the test sequences was covered by positive hybridization with more than five probes," explains Crkvenjakov.

Advances such as this one make it all the more likely that the controversial Human Genome Projectthe Manhattan Project-scale effort to map and sequence the 100,000 or so genes and 3 billion base pairs that comprise the human genome-will be successful. - Joseph Alper 